基準試料としては, 当然一つの試料で多くの分析試料 に対処できるものが望ましく，その比ができるだけ 1 に 近い值をとるものである方が望ましい。

このような条件のもとに，作業分析で得られた代表的 なステンレス鋼中のクロム, ニッケルの日内線返し再現 精度を Table 3 に示す. このデータは, 午前中に測定 の終った試料を, 著者がランダムに $2 \sim 3$ 二抽出し, 午
後再分析を行なわせ，各鋼性約 200 コの分析值より算出 したものである。

この結果, 本装直の繰り返し再現精度は, 湿式化学分 析の精度と同等のものであることが立証でき, 初期の目 的を達することができた。

終りに臨み, 本報告の発表を御許可下さった日本金属 工業K K, 川猗工場工場長, 須永寿夫博士に深謝する.

$$
\text { 分光 研 究 第 } 12 \text { 巻第 } 4 \text { 号 }
$$

\title{
銅スパーク法においてゼラチン使用による感度上昇法
}

\author{
福島弘之*・黒羽敏明** \\ (昭和 38 年 10 月 8 日受理)
}

\section{Effectiveness of Gelatin-Coated Electrodes in Copper Spark Method}

\author{
Hiroyuki FUKUSHIMA* and Toshiaki KUROHA** \\ (*Japan Atomic Energy Research Institute, **Rearch Laboratory, Furukawa Electric Co., Ltd.)
}

\begin{abstract}
The sensitivity of the copper spark method can be increased by coating the electrodes with gelatin. In the proposed method, each electrode is given $0.05 \mathrm{~m} l$ of $0.4 \%$ gelatin solution on its surface and dried under an infrared lamp. The sample solution is likewise dried on the electrodes. With these electrodes, the sensitivity of the method increased threefold at the least and application of the device to determination of rare earth elements in uranium metal proved to be a success.

Distribution and evaporation of sample salts that were traced autoradiographically with $E u^{152+154}$ $\gamma$-emitting isotopes show that a slow and effective evaporation of the sample seems responsible for the increase of the sensitivity, which surmise is confirmed by the obtained curve of intensity vs. time.
\end{abstract}

\section{1. 緒言}

核燃料中に含宗机る微量希土類元素のうち, $G d, S m$, $E u ， D_{Y}$ は熱中性子に対する吸収断面積がきわめて大 きいためにたとえば金属ウランなどで注存在量が 0.01 ppm 以下であることが必要とされる。このような微量 を検出定量するために，普通は化学的分離法により希土 類元素を分離濃縮し，発光分光分析法を適用する．した がって分離操作後の最終分析法として用いられる発光分 光分析法としては, 絶対感度が高いことが第一に必要で

* 日本原子力研究所 (茨城県那珂郡東海村)

** 古河電気工業株式会社中央研究所（東京都品川区二 葉町 3-520)
ある. M. Fred, W.H. Nachtrieb により述べられた銅 スパーク法1がここれの目的に対し広く適用されてい る2)。この報告では銅スパーク法の感度を上昇させるた めに行なった試みについて述べる. 最終分析法の感度が 若干でも上昇するなら，大量の試料を取り扱う繁雑さは 減少し, より迅速な化学分析法の適用をもたらすなど多 くの利益があるからである。

中島, 河口 ${ }^{3)}$ は $E u^{152+154}$ トレーサー学利用して銅ス

1) M. Fred, W.H. Nachtrieb and F.S. Tomkins: J. Opt. Soc. Am., 37, 279 (1947).

2）中島篤之助，高橋正雄，河口広司：日本金属学会 誌, 22, 564 (1958).

3) T. Nakajima and H. Kawaguchi: Spectrochim. Acta, 18, 1479 (1962). 
パーク法におけるスパーク放電による蒸発現象をしらべ ているが，その際電極上の試料分布が電極の周辺に集中 していることをオートラジオグラフにより確認し，した がって効電極の形状によっては放電が有効に試料に作用 しないことを述べている。したがってせっかく分離䟴縮 された試料学もっと有効に蒸発気化させるなら，感度は 当然上昇するものと考えられる.

そこで放電路の分布に影響を与えるものと考えられる 対電極の形状について検討它行なった。 またスパーク 放電の衝撃により試料が飛散する可能性を小さくするこ と，電極上の試料分布が周辺に偏るのを防ぐことを考え て，粒子が大きく移動しにくいコロイド物質を使用する ことを試みた。その結果感度を 3 倍以上上昇させること ができた。

\section{2. 使用装置および操作条件}

実験に使用した装置およびその操作条件を以下にまと めて寺く・操作条件は若干の予備実験や後述の実験にも とついて決めら机た。

Table 1. Operating conditions

\begin{tabular}{|c|c|}
\hline Spectrograph & Fuess $110-\mathrm{H}$ \\
\hline \multirow[t]{2}{*}{ Source } & Raiskij H.V. Spark \\
\hline & $\begin{array}{ll}\mathrm{C}: 0.008 \mu \mathrm{F} & \mathrm{P} \cdot \mathrm{V}: 240 \mathrm{~V} \\
\mathrm{~L}: 750 \mu \mathrm{H} & \mathrm{C} . \mathrm{G}: 2 \mathrm{~mm} \\
\mathrm{R}: 3 \Omega & \mathrm{B}: 13 \text { breaks/ } \\
& \text { half cycle }\end{array}$ \\
\hline Exposure time & $20 \mathrm{sec}$ \\
\hline Slit width & $30 \mu$ \\
\hline Analytical gap & $2 \mathrm{~mm}$ \\
\hline Electrodes & $6 \mathrm{~mm}$ copper rods \\
\hline Emulsion & Kodak SA-1 \\
\hline Developing & $\mathrm{D}-19(1: 1) \quad 6 \min 20^{\circ} \mathrm{C}$ \\
\hline Fixing & $\mathrm{FF}-\mathrm{H}_{4} \quad 6 \min 20^{\circ} \mathrm{C}$ \\
\hline Plate calibration & $\begin{array}{l}\text { 2-step filter method, Seidel } \\
\text { transformation }\end{array}$ \\
\hline
\end{tabular}

\section{3. 対電極の形状の比較検討}

Fig. 1 亿対電極の形状 3 種類を示してあるが, スペク トル線強度安測定した結果は (1) と（3）がよく，同程度 の強度を示した。 また (2) と（3）については上極面に も，すなわち上下両極面に試料をのせたが（3）の方が結 果がよかった。しかし（3）については一般にスパークの 生じる場所が不安定とされており, また両平面を正確に 平行にする事が要求されるが, 試料を両面にのせ 6 組の 試料のスペクトル線強度の再現性の結果, 各元素の平均
偏差率は $\pm 5 \%$ 以内であった。この事から分析定行なら 場合は試料学上下両極面にのせて試料の量を多くとるこ とによって感度を得る点からも平面対平面にする方法を 用いた。 以下ゼラチンをのせて行なら実験もこの方法で 行なった。

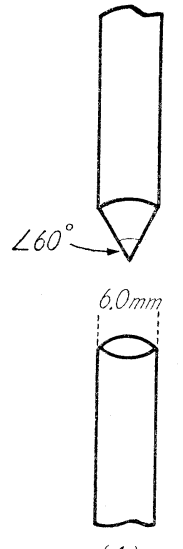

(1)

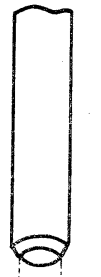

$4.0 \mathrm{~mm}$

(2)

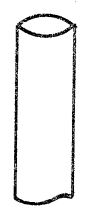

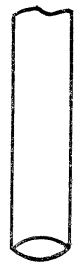

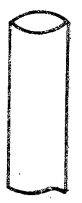

(3)
Fig. 1. Shape of the electrodes used

\section{4. 電極上にゼラチンをのせた場合の検討}

\section{1 試料調整法}

銅電極上にあらかじめ $0.4 \%$ ゼラチン溶液 $50 \lambda$ をの 也乾燥し, 試料它のせ赤外線ランプで乾燥後スパークす る.ゼラチンののせる量が多過ぎると乾燥しにくくゼラ チンによる $C N$ バンドが現われバックグランドに影響 を与える。

\section{2 ゼラチンを用いた場合の感度}

Table 2 にゼラチンをのせた場合とのせない場合の各 元素のスペクトル線強度の比較がのせられている.

Table 2. Comparison of the relative intensities by gelatin coating and uncoating

\begin{tabular}{|c|c|c|c|c|}
\hline & $\AA$ & $\left|\begin{array}{c}\text { Weight of } \\
\text { rare earth } \\
\text { added }\end{array}\right|$ & $\mid \begin{array}{l}\text { Gelatin } \\
\text { uncoating }\end{array}$ & $\begin{array}{l}\text { Gelatin } \\
\text { coating }\end{array}$ \\
\hline$D y$ & 3531.7 & $0.4^{\mu \mathrm{g}}$ & 1.8 & 5.3 \\
\hline $\mathrm{Sm}$ & 3568.9 & 0.8 & 1.1 & 4.1 \\
\hline$Y$ & 3710.3 & 0.2 & 3.5 & 11.9 \\
\hline$Y b$ & 3987.9 & 0.1 & 1.3 & 4.1 \\
\hline$E u$ & 3819.7 & 0.2 & 3.8 & $6.0(4205.1)$ \\
\hline$G d$ & 3768.4 & 0.4 & 0.6 & 1. $2(3358.9)$ \\
\hline
\end{tabular}

Table 2 からわかるようにゼラチンを用いた方が各元 素のスペクトル線強度は 2 倍強の值になっている. 
秃火ゼラチン老用いた場合 $3883 \AA$ band head のCN バンドが幾分出るため，Eu 3819.7 A はその影響を受け るので分析線は $4205.1 \AA$ 老使用乙た。

\section{3 蒸発量の測定}

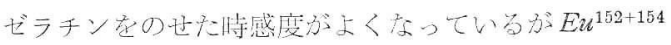
トレーサーで㫮発量について子線スペタトロターターに

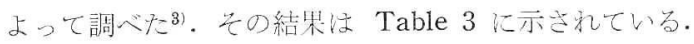

Table 3. Results of measurements of the amount of $\mathrm{Eu}^{152+154}$ isotopes evaporated

\begin{tabular}{l|ll|ll}
\hline & Gelatin uncoating & \multicolumn{2}{|c}{ Gelatin coating } \\
\hline 1 & $77.0 \%$ & $(11.8) \%$ & $45.0 \%$ & $(3.4) \%$ \\
2 & 76.1 & $(10.6)$ & 44.0 & $(5.6)$ \\
3 & 49.5 & $(7.1)$ & 44.4 & $(4.5)$ \\
4 & 66.4 & $(8.2)$ & 20.1 & $(2.7)$ \\
5 & 46.0 & $(8.1)$ & 38.4 & $(3.8)$ \\
\hline$\tilde{x}$ & 63.0 & $(9.2)$ & 38.4 & $(4.0)$ \\
\hline
\end{tabular}

$\mathrm{Eu}^{152+154}$ isotopes are placed on the only lower electrode.

( ) is $\mathrm{Eu}^{152+154}$ isotopes adhead to the upper electrode.

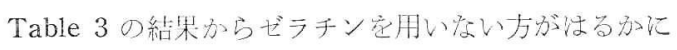
電極加ら蒸発したEUトレーサーダ多い. Table 3 の 結果は下の極の面だにEUトレーサーを使用したので あるが，上下霫極面にE トレレサー起用いた場合も同 様の結果である. Table 3 の（）内に示さ秃た数值は

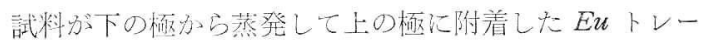

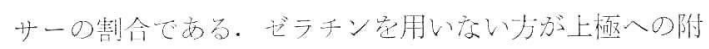
着した量汃多くなっている。

\section{4 オートラジオグラフ}

$E u^{152+154}$ トレーサーを肺いて，ゼラチン交使用した㭙

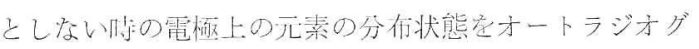
ラフ汢で調ベてみた，その例がFig. 2 に示されている.

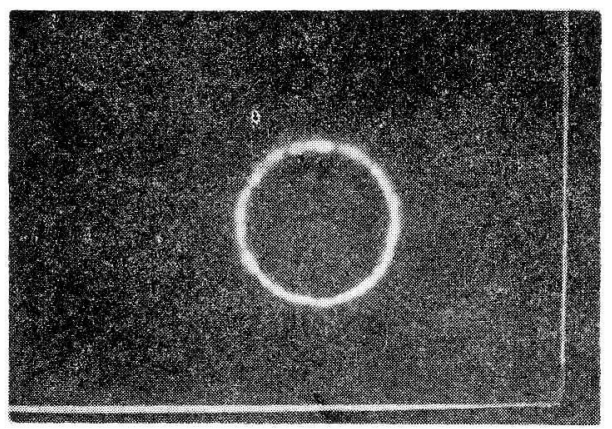

(a) Electrode without coating

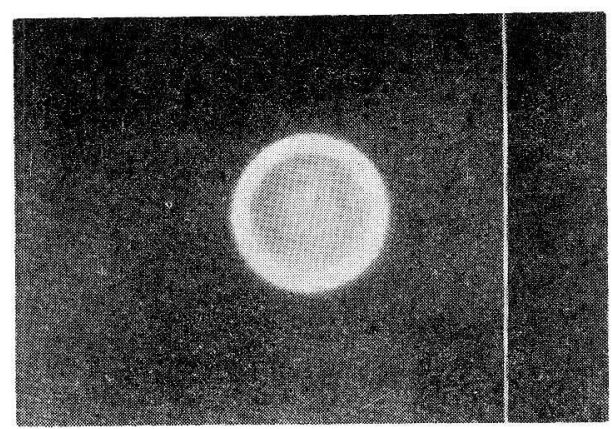

(b) Gelatin-coated electrode

Fig. 2. Distribution of $E u^{152+154}$ on the electrodes by autoradiographic technique

ゼラチン管用いると，元素の分有は周辺に佰ってはいる

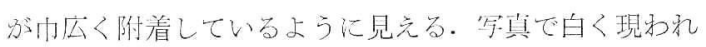
ている部分がトレーサーである.

\section{5. 察}

ゼラチン空用いた場合感度が良くなっているが，ての 点について考えてタるよ，

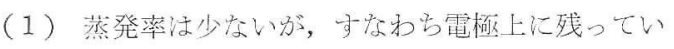
るEuの量が多いが, Moving Plate 法による各元素の

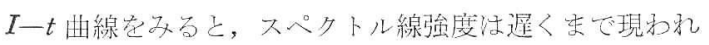
ている事加ら, 元素法しずつ份效に蒸発していると考 兑られる。

（2）オートラジオグラフによるとぜラチン它用いな い場合は，電極周囲の edge に附着しているが，ゼラチ

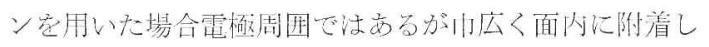
rwb.

（3）分離试料怯塩酸によって溶かされるが，溶液の

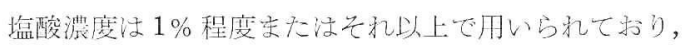
銅電植性侵さ机ない㤹であるが，先際にはごく僅かの 酸化膜が生じていて乾懆の際衣面の变色が生ずる。亦な わ号附着卞べき試料の膜面に $\mathrm{CuCl}_{2}$ が生して分析線感

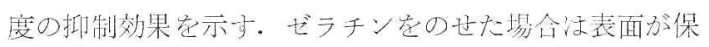
護されて $\mathrm{CuCl}_{2}$ が活とえど生じてこない。

以上気付いた点在述ベたが，それらがゼラチン军用い

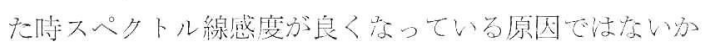
と思李れる。

\section{6. 。検量線と検出下限}

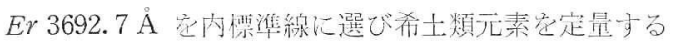
場合の恮量線 Fig. 3 に示した。 
また本法の検出下限炎従来法と比較した結果を Table 4 に示す.

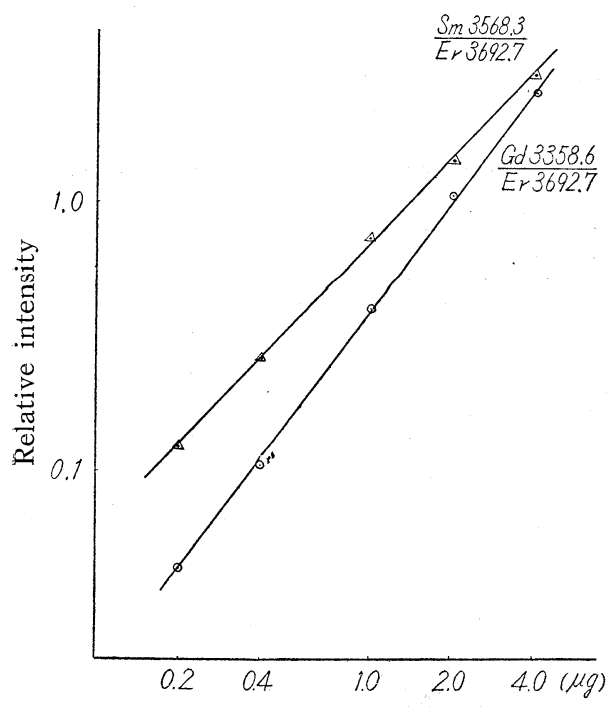

Rare earth concentration

Fig. 3 a. Analytical curves

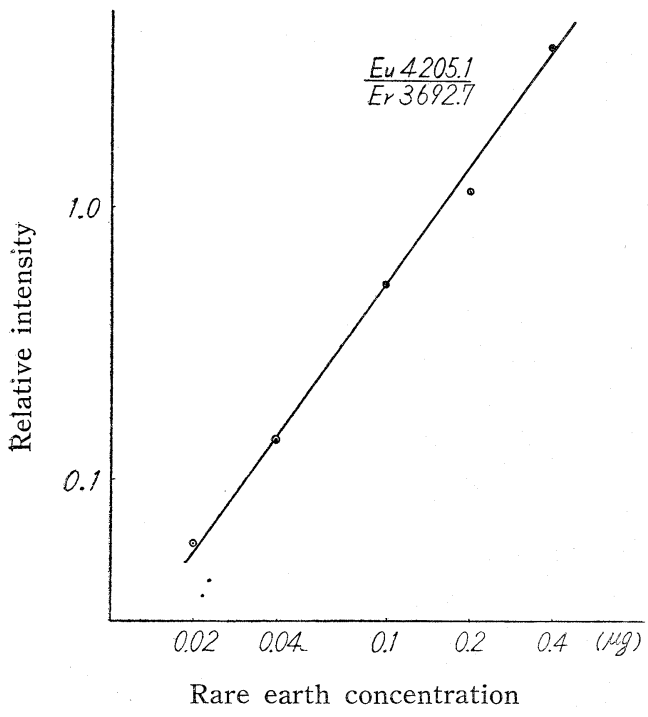

Fig. 3 b. Analytical curve
Table 4. Working range for determination of rare earth

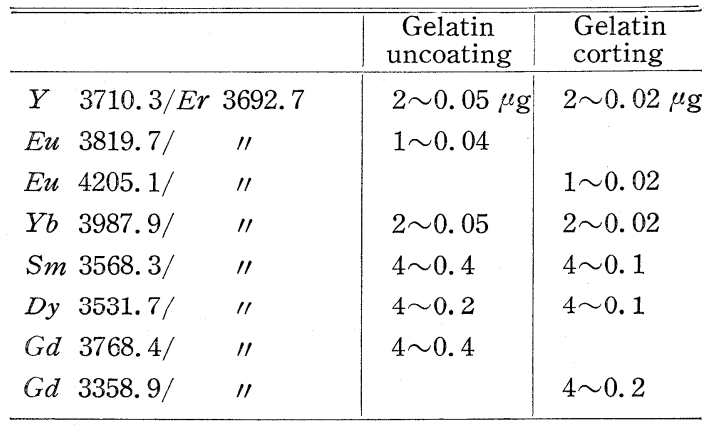

Found values are the amount of rare earth taken on earth plane of both electrodes.

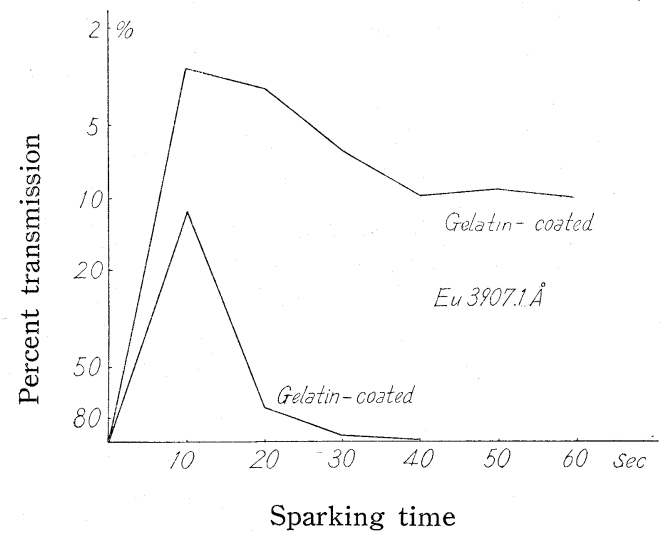

Fig. 4. Variation of the $E u 3907.1 \AA$ intensity with time

Table 4 からかかるように検出下限はゼラチンを用い た方分 2〜4 倍拡大されている. これにより通常 10〜 $50 \mathrm{~g}$ の試料を処理した場合各希土類元素の $0.002 \sim 0.01$ ppm の定量が容易になった。

終りに本報研究中に絶えざる指導をいただきました， 日本原子力研究所中島篤之助博士, 拉よび河口広司研究 員に深く感謝いたします。 